\title{
SYSTEM OF COMPRESSED AIR FOR ELECTROFILTER IN THERMAL POWER PLANT
}

\author{
HADZIAHMETOVIC, H[alima]; DZAFEROVIC, E[jub] \& HODZIC, N[edim]
}

\begin{abstract}
In this paper is explained compressed air pressure drop calculation method, used as a medium for pneumatic valves manipulation. It is important to notice in this case is supposed that we have incompressible air flow, for short pipeline sections. However, for properly system sizing ability, in it's the best way, it is important to know the system function condition, equipment position, and conveying medium characteristics (in this case compressed air). Pipe network arrangement is also very important for system sizing, and this paper is explained all that is needed for pipe network, to secure as simple and technical correct way of air supplying to the consumer, pneumatic valve. In this paper is presented an example of compressed air pipeline sizing used for valve manipulation, as part of a ash pneumatic conveying system.

Keywords: Pipeline, compressor, pressure drop, pneumatic conveying, pneumatic valve
\end{abstract}

\section{INTRODUCTION}

Recently, much attention is paid to preserving the environment, and build systems that prevent pollution of the environment. Thermal power plants are one of the biggest environmental polluters. In the process of electricity production as coal combustion products occur large amounts of waste material. Transportation and disposal of fly ash and bottom ash are among the vital technological systems of each power plant that burns coal. The system of transport of fly ash and bottom ash in the thermal power plant can be: transportation by belt conveyors, transportation with dumper-trucks, hydraulic transport and pneumatic conveying.

The pneumatic ransport involves the transportation powder, granular and piece of material and is based on the phenomenon that at the appropriate velocity of air in the pipeline, the solid particles are brought in the desired direction. Selection and efficiency of pneumatic transport depends of physical and chemical characteristic of the fly ash [3].

In this paper is explained compressed air pressure drop calculation method in pneumatic conveying. For properly system sizing ability, it is important to know the system function condition, pipe network, equipment position, and conveying medium characteristics (in this case compressed air).

In many systems, compressed air, there are significant and untapped opportunities for saving energy, including energy recovery, pressure reduction, reducing leakage losses and optimization of systems and control systems, as well as the proper choice of the compressor. When planning an investment in building a compressed air system, it is necessary to examine and evaluate, as well as possible future claims that this system has to fulfill, as well as all other possible influences on the compressed air system $[2,4,6]$.

In the system of transport fly ash below electrofilter, flue gas channel and steam air heater is used a number of pneumatic valves, as the basic elements of regulation and control system for pneumatic transport of fly ash. For the correct operation of all pneumatic valves is necessary to make the choice of appropriate compressor and pipeline distribution network for them. In this paper is presented a system of preparation and distribution of compressed instrument air to the consumer in the system of internal pneumatic transport of fly ash under the electrofilter, flues and steam air heaters. System of compressed air for electrofilter is an integral part of a whole, the pneumatic transport of fly ash for the silo. The quantity of fly ash shown in table 1 and list of design input data are shown in tables 2 and 3 .

\begin{tabular}{|c|c|}
\hline Input data & Value \\
\hline Total ash, bottom and fly ash: & $175-240 \mathrm{t} / \mathrm{h}$ \\
\hline Fly ash: & $\begin{array}{l}162,5-232,2 \\
t / h\end{array}$ \\
\hline $\begin{array}{l}\text { Ash from boiler hoppers and air preheater hopper: } \\
\text { (this ash is included in the sum for fly ash) }\end{array}$ & $13,0-17,9 \mathrm{t} / \mathrm{h}$ \\
\hline
\end{tabular}

Tab 1 . The quantity of ash produced by one unit

\begin{tabular}{|c|c|}
\hline Input data & Value \\
\hline Bulk density of fly ash & $0,7 \mathrm{t} / \mathrm{m}^{3}$ \\
\hline Specific mass density & $2,1 \mathrm{~g} / \mathrm{cm}^{3}$ \\
\hline Average solid particle size, $\mathrm{d}_{50}$ & $100 \mathrm{microns}$ \\
\hline
\end{tabular}

Tab 2. Design data

\begin{tabular}{|c|c|}
\hline Input data & Value \\
\hline $\begin{array}{c}\text { Long distance fly ash pneumatic } \\
\text { conveying }\end{array}$ & $\begin{array}{c}258 \mathrm{t} / \mathrm{h} \text { per unit(including } 15 \% \\
\text { reserve) }\end{array}$ \\
\hline Slurry flow range & $326-355 \mathrm{~m}^{3} / \mathrm{h}$ \\
\hline Maximum possible slurry flow & $390 \mathrm{~m}^{3} / \mathrm{h}$ \\
\hline
\end{tabular}

Tab 3. Capacity data of the system

\section{TECHNICAL DESCRIPTION}

Base purpose of reservoir within compressor facility is that together with compressor regulation adjusts supply of compressed air towards consumption needs.

2.1 Source of compressed air supply for manipulation and control of pneumatic valves of internal fly ash transport under electrofilter (EPS)

Besides reservoir with its volume reduces pressure pulsations, and in case of high consumption provide 
needs for compressed air. Reservoirs, like all other vessels under pressure belong to inspection control and law regulation during construction and exploitation.

\subsection{Compressed air distribution}

Compressed air is distributed by seamless steel galvanized pipelines. Distribution pipeline is oriented towards consumers, apropos to all valves on pneumatic drive which are located under electrofilter (EPS) of Unit 1 and Unit 2, and to the consumers in pump stations 1 and 2. In function of assigned pressure, complete pipeline is dimensioned, apropos diameters of certain sections are specified. In analysis of installations under pressure, all pressure drops are calculated between compressor station and consumers.

\subsection{Compressed air consumers}

Compressed air is used for manipulation and control in pneumatic transport process as well as for manipulation of pneumatic valves which are within automatic control of pneumatic transport.

Locations which are supplied with compressed air: pressure vessels for pneumatic fly ash transport, air transport pipeline, armatures of ash receiver (plate gate valves), ash transport pipelines and pneumatic valves in bager station.

Consumers, apropos places which are needed to be supplied with compressed air, altogether there are 226 pieces. Function of these valves is in program control of fly ash transport process which is managed by PLC. Safe operation of installation, apropos maintaining pressure in installation within limitations of minimal and maximal permissible pressure is supplied with regulation system which is located in the compressor. Compressor is in mutual automatic operation with reservoir of instrumental air where pressure should be between $6,3-$ 7,5 bars.

When pressure in reservoir drops under 7,5 bars, and reaches value of minimum permissible operation pressure $\mathrm{p}_{\min }=6,3$ bars, automatically one compressor activates until maximal wanted pressure is not reached.

\section{SELECTION OF COMPRESSOR FOR COMPRESSED AIR UNDER ELECTROFILTER (ESP)}

a. Air consumption by consumer for transmition in block $1: \mathrm{Q}_{1}=53 \mathrm{~m}^{3} / \mathrm{h}$.

b. Air consumption by consumer for transmition in block 2: $\mathrm{Q}_{2}=53 \mathrm{~m}^{3} / \mathrm{h}$.

c. Air consumption by consumer for transmition in pump stations 1 and 2 like consumers on air preheaters and under channel of flue gases: $Q_{3}=15$ $\mathrm{m}^{3} / \mathrm{h}$.

d. Total air consumption increased for $20 \%: \mathrm{Q}=1,2$. $\left(\mathrm{Q}_{1}+\mathrm{Q}_{2}+\mathrm{Q}_{3}\right)=1,2 \cdot 121=145,2 \mathrm{~m}^{3} / \mathrm{h}$.

On the basis of calculated consumption of $145,2 \mathrm{~m}^{3} / \mathrm{h}$ compressor of firm Atlas Copco is selected:

Type: GA15 ${ }^{+}$, Capacity: $160 \mathrm{~m}^{3} / \mathrm{h}$, Operation pressure: 7,5 bara , Power of electromotor: $15 \mathrm{~kW}$, Noise level: 64 dB, Dimensions 1400 x 1225 x 650 [1].

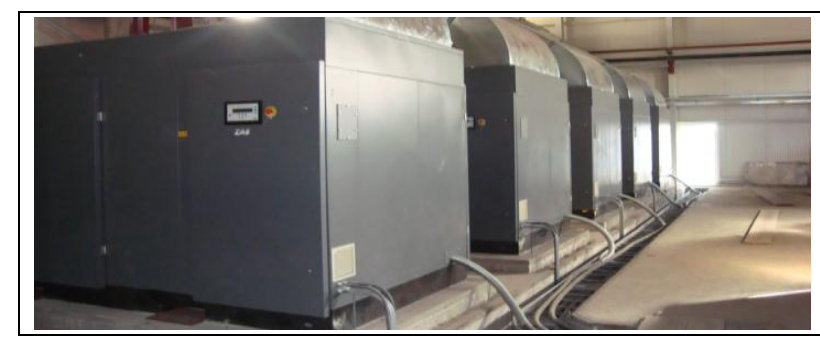

Fig. 1. Compressor

On the base of selected compressor and accrding to Atlas Copco recommendation absorption dryers type CD 44 (2 piece) are chosen (Fig. 1). And on the base of experience in designing system of compressed air, instrumental air reservoir is selected, volume $V=2 \mathrm{~m}^{3}$.

\subsection{Pipeline calculatuon at the outlet of the compressor}

\subsubsection{Air density by pressure and ambient temperature}

Air density in ambient temperature and pressure be calculated according to the following :

$$
\rho_{1}=\frac{p_{1}}{R \cdot T_{1}}
$$

where $\mathrm{p}_{1}=1$ bar is pressure of ambient air, $\mathrm{t}_{1}=20^{\circ} \mathrm{C}$ is ambient temperatute and the gas constant is $\mathrm{R}=8,314$ $\mathrm{J} / \mathrm{mol} \mathrm{K}$.

$$
\rho_{1}=\frac{100000}{(273+20) \cdot 287}=1,189 \mathrm{~kg} / \mathrm{m}^{3}
$$

\subsubsection{Air density at outlet of the compressor}

Air density in pipeline at outlet of the compressor is according calculation to equation (1) as follows:

$$
\rho_{2}=\frac{8,5 \cdot 10^{5}}{287 \cdot(25+273)}=9,9385 \mathrm{~kg} / \mathrm{m}^{3}
$$

where $\mathrm{T}_{2}=25^{\circ} \mathrm{C}$ is temperature at the outlet of the compressor and $\mathrm{p}_{2}=1+7,5=8,5 \mathrm{bar}=8,5 \cdot 10^{5} \mathrm{~Pa}$ is pressure at outlet of the compressors.

\subsubsection{Quantity of compressed air}

Quantity of compressed air be calculated according to the following:

$$
\begin{gathered}
Q_{2}=\frac{M_{1}}{\rho_{2}} \\
Q_{2}=\frac{M_{1}}{\rho_{2}}=\frac{0,05285 \mathrm{~kg} / \mathrm{s}}{9,7745 \mathrm{~kg} / \mathrm{m}^{3}}=0,0053 \mathrm{~m}^{3} / \mathrm{s}
\end{gathered}
$$

where mass air flow $\mathrm{M}_{1}=\rho_{1} \cdot \mathrm{Q} \rightarrow \mathrm{M}_{1}=1,189 \cdot .160$ $=190,24 \mathrm{~kg} / \mathrm{h}=0,05285 \mathrm{~kg} / \mathrm{s}$.

\subsubsection{Pipeline dimensioning}

Internal pipeline diameter is given by:

$$
d=\sqrt{\frac{4 \cdot Q_{2}}{\pi \cdot v}}
$$


Assumed air velocity for pipeline flow $\mathrm{v}=5 \mathrm{~m} / \mathrm{s}$ and

$$
d=\sqrt{\frac{4 \cdot 0,0053}{\pi \cdot 5}}=0,0368 \mathrm{~m}=37 \mathrm{~mm}
$$

Nominal pipe diameter DN $32(\varnothing 42,4 \times 2,6)$ is accepted.

\subsection{Calculation of compressed air pressure drop for section 1-1}

Pressure drop on line of compressed air is given by:

$$
\Delta p_{1}=\lambda \frac{L}{D} * \frac{v^{2}}{2} \rho_{2}+\sum \xi \frac{v^{2}}{2} \rho_{2}
$$

where are $: \lambda$ - coefficient of air friction in pipeline, $\mathrm{L}$ - pipeline length, D - internal pipeline diameter, $\mathrm{v}$ - air velocity in pipeline, $\rho$-air density in pipeline and $\xi-$ local losses [4,5].

\subsubsection{Pipeline characteristics section 1-1}

Characteristics of pipeline section 1-1 are shown in table 4 .

\begin{tabular}{|c|c|}
\hline Input data & Value \\
\hline Pipeline length $(\mathrm{m})$ & $300[\mathrm{~m}]$ \\
\hline Air velocity in pipeline $(\mathrm{m} / \mathrm{s})$ & $5[\mathrm{~m} / \mathrm{s}]$ \\
\hline Internal pipe harshness $(\mathrm{mm})$ & $0,05[\mathrm{~mm}]$ \\
\hline Internal pipe diameter $(\mathrm{mm})$ & $37,2 \mathrm{~mm}(\mathrm{DN} 32, \varnothing 42,4$ \\
& x 2,6) \\
\hline
\end{tabular}
Tab 4. Pipeline characteristics section $1-1$

\subsubsection{Air density with operation parameters}

Air density in pipeline at outlet of the compressor is according calculation to equation as follows (1):

$$
\rho_{2}=\frac{8,5 \cdot 10^{5}}{287 \cdot(25+273)}=9,9385 \mathrm{~kg} / \mathrm{m}^{3}
$$

where $\mathrm{T}_{2}=25^{\circ} \mathrm{C}$ is temperature at the outlet of the compressor and $\mathrm{p}_{2}=1+7,5=8,5$ bar $=8,5 \cdot 10^{5} \mathrm{~Pa}$ is pressure at outlet of the compressors.

\subsubsection{Determination of air circuit in pipeline}

Reynolds number can be determined by:

$$
\begin{gathered}
\operatorname{Re}=\frac{v \cdot D \cdot \rho_{2}}{\eta_{2}} \\
\operatorname{Re}=\frac{5 \cdot 0,0372 \cdot 9,9385}{18,81 \cdot 10^{-6}}=0,98 \cdot 10^{5}
\end{gathered}
$$

$\mathrm{Re}>2300$-turbulent circuit

\subsubsection{Determination of air viscosity and friction coefficient}

Dynamic viscosity of air on temperature $T_{2}$ can be determined by [5]:

$$
\eta_{2}=\eta_{0} \frac{T_{b}+C}{T_{2}+C}\left(\frac{T_{2}}{T b}\right)^{\frac{3}{2}}
$$

where $\mathrm{T}_{2}=25^{\circ} \mathrm{C}=298 \mathrm{~K}$ is temperature at the output of the compressor, $\mathrm{T}_{\mathrm{b}}=273 \mathrm{~K}$ is air temperature in normal condition and $\eta_{0}=17,3 \cdot 10^{-6} \mathrm{~Pa}$.

$$
\eta_{2}=17,3 \cdot 10^{-6} \frac{273+124}{298+124} \underbrace{\left(\frac{298}{273}\right)^{\frac{3}{2}}}_{2,4}=18,56 \cdot 10^{-6} \mathrm{Pas}
$$

\subsubsection{Friction coefficient of air and pipeline}

Internal harshness of pipe is $\mathrm{K}=0,05 \mathrm{~mm}$ and internal pipe diameter $\mathrm{D}=37,2 \mathrm{~mm}(\mathrm{DN} 32, \varnothing 42,4 \times 2,6)$ and relative pipe harshness should be calculated according to the following:

$$
\frac{K}{D}=\frac{0,05}{37,2}=0,00134=13,44 \cdot 10^{-4}
$$

where $\lambda$ is friction coefficient of air in pipeline and can be determined by:

$$
\lambda=f\left(\operatorname{Re}, \frac{K}{D}\right)=0,0225
$$

\subsubsection{Friction coefficient of air in pipeline}

\begin{tabular}{|c|c|c|}
\hline Resistance coefficient for bend $90^{\circ}$ & $\xi_{K_{1}}=0,3$ & $10 \mathrm{pcs}$ \\
\hline Resistance coefficient for bend $45^{\circ}$ & $\xi_{K_{2}}=0,3$ & $4 \mathrm{pcs}$ \\
\hline Resistance coefficient for T-piece & $\xi_{T}=0,6$ & $14 \mathrm{pcs}$ \\
\hline \multicolumn{2}{|c|}{ Total of local losses in pipeline: $\Sigma \xi i=0,3 \cdot 10+0,3 \cdot 4+0,6 \cdot 14=12,6$} \\
\hline
\end{tabular}

Using equation (4), the calculated pressure drop on line for compressed air for section 1-1:

$$
\Delta p_{1}=0,0225 \frac{300}{0,0372} \cdot \frac{5^{2}}{2} \cdot 9,9385+12,6 \cdot \frac{5^{2}}{2} \cdot 9,9385=0,241 \mathrm{bar}
$$

where are $: \lambda$ - coefficient of air friction in pipeline, $L$ pipeline length, D - internal pipeline diameter, $\mathrm{v}$ - air velocity in pipeline, $\rho$-air density in pipeline and $\xi-$ local losses.

\subsection{Calculation of compressed air pressure drop for section $2-2$}

Pressure drop on line of compressed air can be determined by formula (4).

\subsubsection{Pipeline characteristics section 2-2}

Characteristics of pipeline section $2-2$ are shown in table 6 .

\begin{tabular}{|c|c|}
\hline Input data & Value \\
\hline Pipeline length & $70[\mathrm{~m}]$ \\
\hline Air velocity in pipeline & $5[\mathrm{~m} / \mathrm{s}]$ \\
\hline Internal pipe harshness & $0,05[\mathrm{~mm}]$ \\
\hline Internal pipe diameter & $28,5 \mathrm{~mm}(\mathrm{DN} 25, \varnothing 33,7 \times 2,6)$ \\
\hline
\end{tabular}

Tab 6. Pipeline characteristic section 2-2 


\subsubsection{Air density with operation parameters}

Air density in pipeline at outlet of the compressor is according calculation to equation (1) as follows:

$$
\rho_{2}=\frac{8,5 \cdot 10^{5}}{287 \cdot(25+273)}=9,9385 \mathrm{~kg} / \mathrm{m}^{3}
$$

where $\mathrm{T}_{2}=25^{\circ} \mathrm{C}$ is temperature at the outlet of the compressor and $\mathrm{p}_{2}=1+7,5=8,5 \mathrm{bar}=8,5 \cdot 10^{5} \mathrm{~Pa}$ is pressure at outlet of the compressors.

\subsubsection{Determination of air circuit in pipeline}

Using equation (5), the calculated Reynolds number:

$$
\operatorname{Re}=\frac{5 \cdot 0,0285 \cdot 9,9385}{18,81 \cdot 10^{-6}}=0,753 \cdot 10^{5}
$$

$\operatorname{Re}>2300$ - turbulent circuit.

\subsubsection{Determination of air viscosity and friction coeff.}

Using equation (6), the calculated dynamic viscosity of air on temperature $\mathrm{T}_{2}$ :

$$
\eta_{2}=\eta_{0} \frac{T_{b}+C}{T_{2}+C}\left(\frac{T_{2}}{T_{b}}\right)^{\frac{3}{2}}
$$

Temperature at the output of the compressor is $\mathrm{T}_{2}=$ $25^{\circ} \mathrm{C}=298 \mathrm{~K}$, air temperature in normal condition is $\mathrm{T}_{\mathrm{b}}$ $=273 \mathrm{~K}$ and $\eta_{0}=17,3 \cdot 10^{-6} \mathrm{~Pa}$.

$$
\eta_{2}=17,3 \cdot 10^{-6} \frac{273+124}{298+124} \underbrace{\left(\frac{298}{273}\right)^{\frac{3}{2}}}_{2,4}=18,56 \cdot 10^{-6} \text { Pas }
$$

\subsubsection{Friction coefficient of air and pipeline}

Internal harshness of pipe is $\mathrm{K}=0,05 \mathrm{~mm}$ and internal pipe diameter $\mathrm{D}=28,5 \mathrm{~mm}(\mathrm{DN} 40, \varnothing 33,7 \times 2,6)$ and relative pipe harshness should be calculated according to the following:

$$
\frac{K}{D}=\frac{0,05}{28,5}=0,00175=17,54 \cdot 10^{-4}
$$

where $\lambda$ is friction coefficient of air in pipeline and can be determined by:

$$
\lambda=f\left(\operatorname{Re}, \frac{K}{D}\right)=0,0232
$$

\subsubsection{Friction coefficient of air and pipeline}

\begin{tabular}{|l|l|l|}
\hline Resistance coefficient for bend $90^{\circ}$ & $\xi_{K_{1}}=0,3$ & $7 \mathrm{pcs}$ \\
\hline Resistance coefficient for bend $45^{\circ}$ & $\xi_{K_{2}}=0,3$ & $7 \mathrm{pcs}$ \\
\hline Resistance coefficient for T-piece & $\xi_{T}=0,6$ & $12 \mathrm{pcs}$ \\
\hline Total of local losses in pipeline: $\Sigma \xi i=0,3 \cdot 7+0,3 \cdot 7+0,6 \cdot 12=11,4$ \\
\hline
\end{tabular}

Tab 7. Friction coefficient of air in pipeline
3.3.7 Pressure drop on line of compressed air for section 2-2

Using equation (4), the calculated pressure drop on line for compressed air for section 2-2:

$\Delta p_{2}=0,0232 \frac{70}{0,0285} \cdot \frac{5^{2}}{2} \cdot 9,9385+11,4 \cdot \frac{5^{2}}{2} \cdot 9,9385=0,08495 \mathrm{bar}$

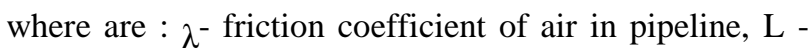
pipeline length, D - internal pipeline diameter, $\mathrm{v}$ - air velocity in pipeline, $\rho$-air density in pipeline and $\xi-$ local losses. Pressure drop in absorption dryer is $\Delta p_{3}=0,12 \mathrm{bar}$ and filter pressure drop is $\Delta p_{4}=0,20 \mathrm{bar}$.

\subsubsection{Total pressure drop can be determined by:}

$$
\begin{gathered}
\Delta p=\Delta p_{1}+\Delta p_{2}+\Delta p_{3}+\Delta p_{4} \\
=0,241+0,08495+0,12+0,20=0,64595 \text { bar. }
\end{gathered}
$$

\section{CONCLUSION}

The application of compressed air is of great importance in industry, and improving the system of handling shut-off bodies for the purpose of putting the system in automatic mode. The purpose of this paper is introduction with system sizing method, and its elements, required for instrumental, instrumental air supply to the consumer, valve. Pneumatic valves are basically valves that do not require much energy that is significantly lower power consumption compared to the electric valves which are also expensive. This calculation can be applied to any type of industrial facilities that can make handling shut-off elements, pneumatic (compressed air), and thus achieve significant energy savings and money. His great safety during use results in high energy consumption, which is the final outcome is the high cost of compressed air. Compressed air as an energy source is 50 times more expensive than natural gas and oil, and 10 times more expensive than the cost of electricity. For this fact is even more obvious is the fact that $95 \%$ of compressed air products air compressors, which are powered by electricity, and therefore not so surprising that the total industrial electricity costs $10 \%$ is attributed only to produce compressed air.

\section{REFERENCES}

[1] Atlas Copco Airpower NV, (2010), Compressed Air Manual 7th edition, Belgium, ISBN 9789081535809

[2] Bloch, H. P., (2006), A Practical Guide to Compressor Technology, 2nd Ed., ISBN 0-471-727930-8, John Wiley \& Sons, Hoboken, New Jersey

[3] Bloch, H. P., (2006), Compressors and Modern Process Applications, ISBN 0-471-72792-X, John Wiley \& Sons, Hoboken, New Jersey

[4] Dzaferović E., Hadziahmetović H., (2011), Pneumatic conveying, ISBN 978-9958-601-35-4, Faculty of Mechanical Engineering Sarajevo, Bosnia and Herzegovina

[5] Hadziahmetovic, H. \& Dzaferovic, E., (2009), Ash pneumatic conveying from existing silos no. 4 to two new silos and ash loading in autocisterns - The 20th INTERNATIONAL DAAAM SYMPOSIUM "Intelligent Manufacturing \& Automation: Theory, Practice \& Education", 25-28th November 2009, Vienna, Austria

[6] Mills D.,(2004), Pneumatic Conveying Design Guide, Second Edition, ISBN: 0750654716, Butterworth- Heinemann, UK 